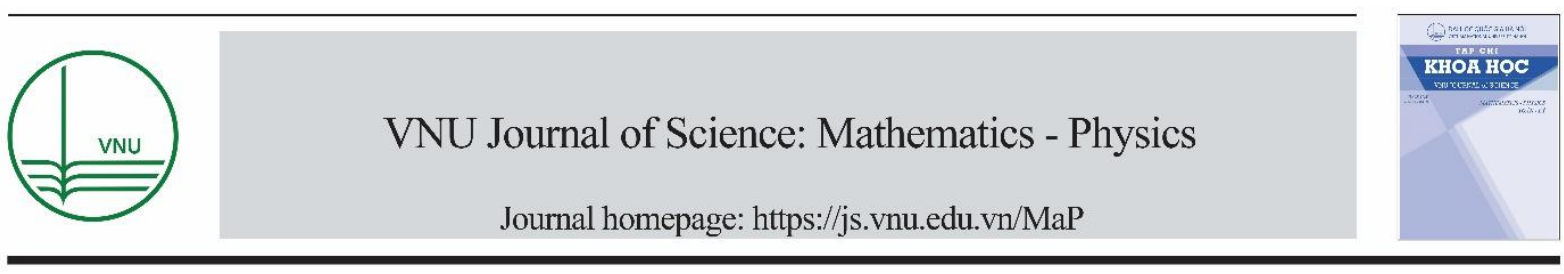

Original Article

\title{
A Comparative Study on Two Different Methods for Calculating Gravity Effect of an Uneven Layer: Application to Computation of Bouguer Gravity Anomaly in the East Vietnam Sea and Adjacent Areas
}

\author{
Luan Thanh Pham* \\ Faculty of Physics, VNU University of Science, 334 Nguyen Trai, Thanh Xuan, Hanoi, Vietnam \\ Received 26 April 2020 \\ Revised 06 May 2020; Accepted 20 June 2020
}

\begin{abstract}
Calculation of gravity anomaly caused by an uneven layer is essential for quantitative interpretation. By comparing calculated anomalies with observed anomalies, we may infer some parameters of subsurface structures. There are many different methods for computing gravity effect of an uneven layer. This paper presents a comparative study of two different forward methods such as the space domain method and the frequency domain method. The performance of each method was evaluated on two synthetic models. Finally, the more effective method was applied to calculate Bouguer gravity anomaly in the East Vietnam Sea and adjacent areas using the latest available dataset from the TOPEX mission.

Keywords: Forward method, space domain, frequency domain, Bouguer gravity anomaly, Vietnam.
\end{abstract}

\section{Introduction}

The purpose of gravity methods in natural resources exploration is to determine the geometric parameters of the density structures, including depth, slope, lateral boundaries, etc [1-7]. Knowledge of the parameters of the gravity sources can be important for optimizing drilling operations as well as estimating mineral deposits [8-10]. The gravity anomalies can be calculated from known or assumed information and then compared with measured gravity anomalies to determine some source parameters. A range of different methods have been developed to calculate gravity anomalies caused by density structures. The methods can generally be divided into two main groups, namely the space

\footnotetext{
${ }^{*}$ Corresponding author.

Email address: luanpt@hus.edu.vn
}

https//doi.org/ 10.25073/2588-1124/vnumap.4515 
domain methods, and the frequency domain methods. Numerous methods have been developed to calculate gravity anomaly of 2D structures in the space domain [11-16]. Some authors (e.g. [17-23]) derived gravity anomaly expressions of 3D structures in the space domain. Several other authors have presented the different methods for calculating gravity effect of 3D structures in the frequency domain and converted the anomalies into space domain by the inverse Fourier transformation for further analysis [24-27]. The above forward methods are essential in interpreting gravity data, because they provide the basic equations for automatically estimating subsurface structures.

In this paper, I aim to review the performance of the popular forward methods such as the space domain method of Rao et al. (1990) and the frequency domain method of Parker (1973) [20, 24]. These methods were tested on a simple model and then on a complex model. Additionally, Bouguer gravity anomaly in the East Vietnam Sea and adjacent areas were also calculated using the more effective method.

\section{Methods}

In order to calculate the gravity anomaly caused by an uneven layer, Rao et al. (1990) developed a space domain method that divided the uneven subsurface structure into many rectangular prisms. In a Cartesian coordinate system, let $T$ and $W$ be the half thickness and half width of one such prismatic source with $Z_{1}$ and $Z_{2}$ are the depths to the top and bottom, respectively. The gravity anomaly of a prism source at any observation $(\mathrm{x}, \mathrm{y})$ of a rectangular mesh is given as [20]

$$
\Delta g(x, y)=\left.G \Delta \rho\left(z \operatorname{atan} \frac{X Y}{z R}+\frac{X}{2} \ln \frac{R-Y}{R+Y}+\frac{Y}{2} \ln \frac{R-X}{R+X}\right)\right|_{X_{1}} ^{X_{2}} \mid \begin{array}{|l|l}
Y_{2} & Z_{2} \\
Y_{1} & Z_{1}
\end{array}
$$

where

$$
X_{1}=x+T, X_{2}=x-T, Y_{1}=y+W, Y_{2}=y-W, R=\sqrt{X^{2}+Y^{2}+Z^{2}},
$$

$G$ is the universal gravitational constant and $\Delta \rho$ is density contrast of the layer. The total gravity anomaly $\Delta g_{\text {total }}(x, y)$ is determined by adding the anomaly of all prismatic sources.

Another method was developed by Parker (1973) for rapid calculating gravity and magnetic anomalies in the frequency domain. The method used a sum of the Fourier transforms of the powers of the interface topography $h$ to calculate gravity anomalies. Following Parker (1973), the total gravity anomaly $\Delta g_{\text {total }}(x, y)$ caused by an uneven layer is given by [24]

$$
\Delta g_{\text {total }}(x, y)=2 \pi G \Delta \rho z_{0}+F^{-1}\left[2 \pi G \Delta \rho e^{\left(-|k| z_{0}\right)} \sum_{n=1}^{\infty} \frac{(-|k|)^{n-1}}{n !} F\left[h(x, y)^{n}\right]\right]
$$

where $F[]$ is the Fourier transform operator, $F^{-1}[]$ is the inverse Fourier transform operator, $z_{0}$ is the mean depth of the interface and $k=\sqrt{k_{x}^{2}+k_{y}^{2}}$ with $k_{x}$ and $k_{y}$ are the wavenumbers in the $x$ and $y$ directions, respectively.

\section{Synthetic models}

In this section, I designed two different theoretical models with density contrast of $200 \mathrm{~kg} / \mathrm{m}^{3}$ to test the efficiency of the methods. 


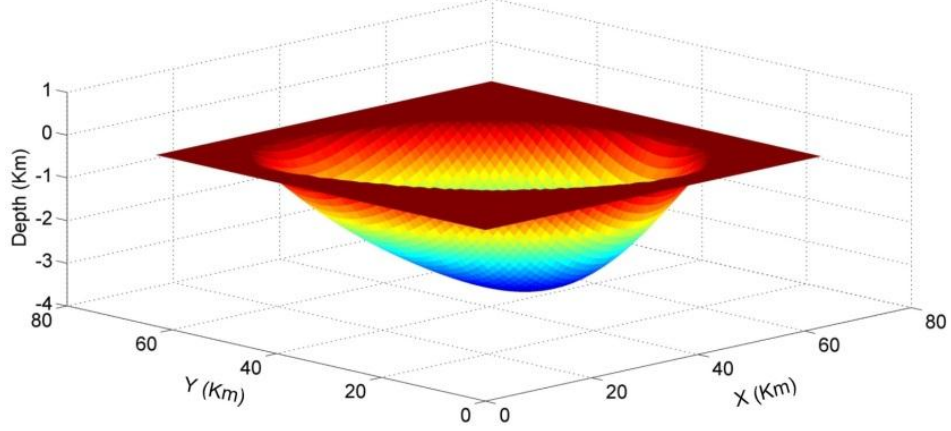

Figure 1 . The 3D view of the first model.
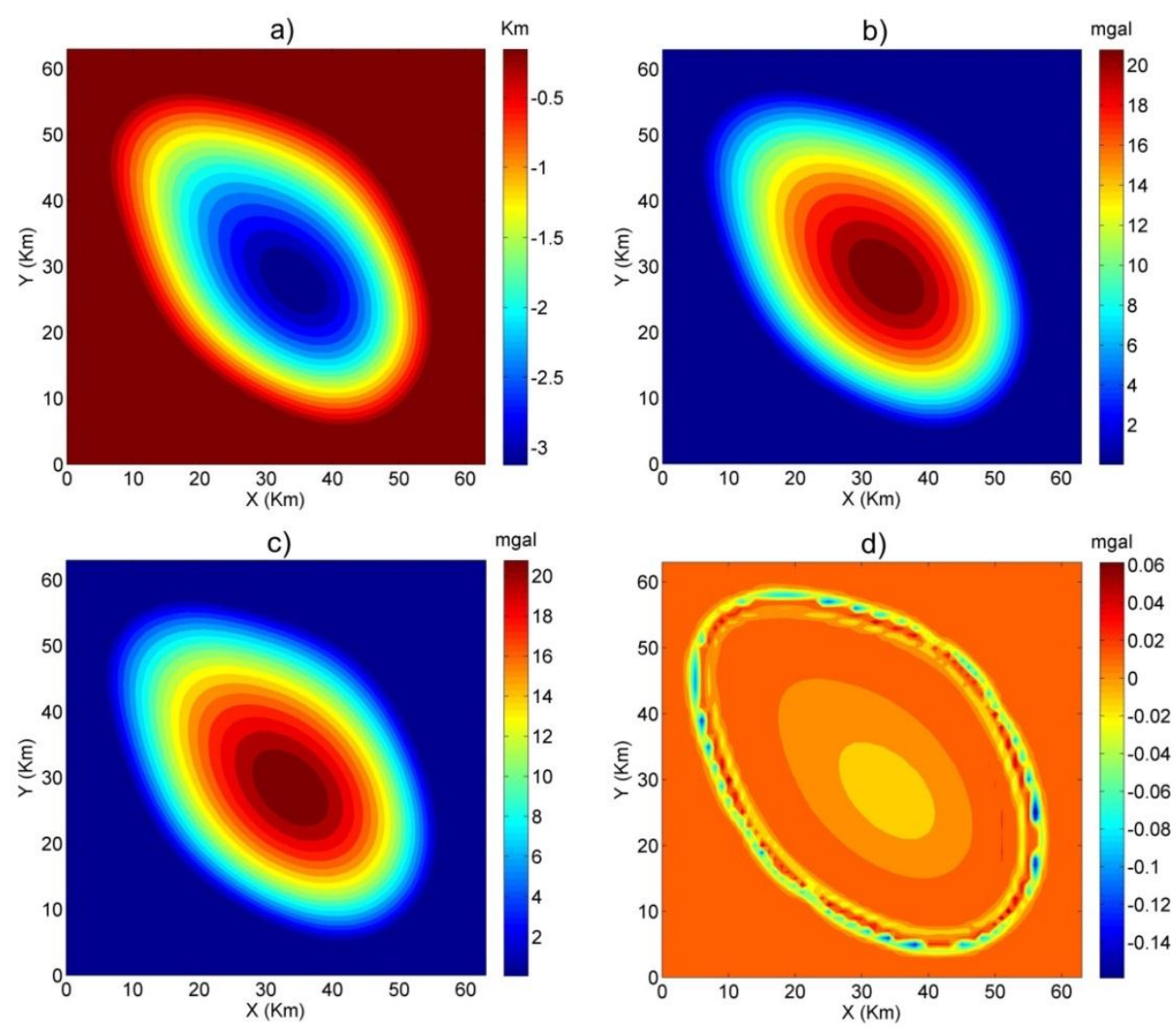

Figure 2. (a) The plan view of the first model, (b) The gravity anomalies calculated by the space domain method, (c) The gravity anomalies calculated by the frequency domain method respectively, (d) The difference between the results in Figure $2 \mathrm{~b}$ and $2 \mathrm{c}$.

Figure 1 displays the 3D view of the first model. Figure 2a displays the plan view of the model. Figure $2 \mathrm{~b}$ and $2 \mathrm{c}$ show the gravity anomalies calculated by the space domain method and the frequency domain method respectively. It can be observed that the results obtained from applying the methods are similar. The difference between these results is shown in Figure 2d. We can see that these differences are insignificantly small and are in the range of $-0.25-+0.06$ mgal. The root mean square 
(RMS) error between them is only $0.0213 \mathrm{mgal}$. We note here that the frequency domain method took only about $0.1838 \mathrm{~s}$ to compute the gravity anomalies at $64 \times 64$ grid nodes using a personal computer with Intel (R) Core (TM) i3 at $2.40 \mathrm{GHz}$ CPU, while the space domain method took about $22 \mathrm{~s}$ to make the gravity model.

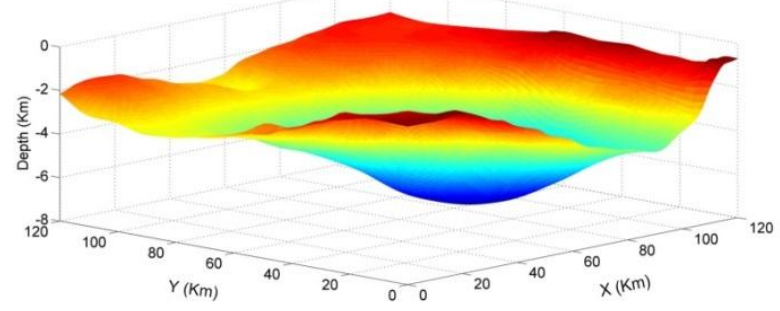

Figure 3. The 3D view of the second model.
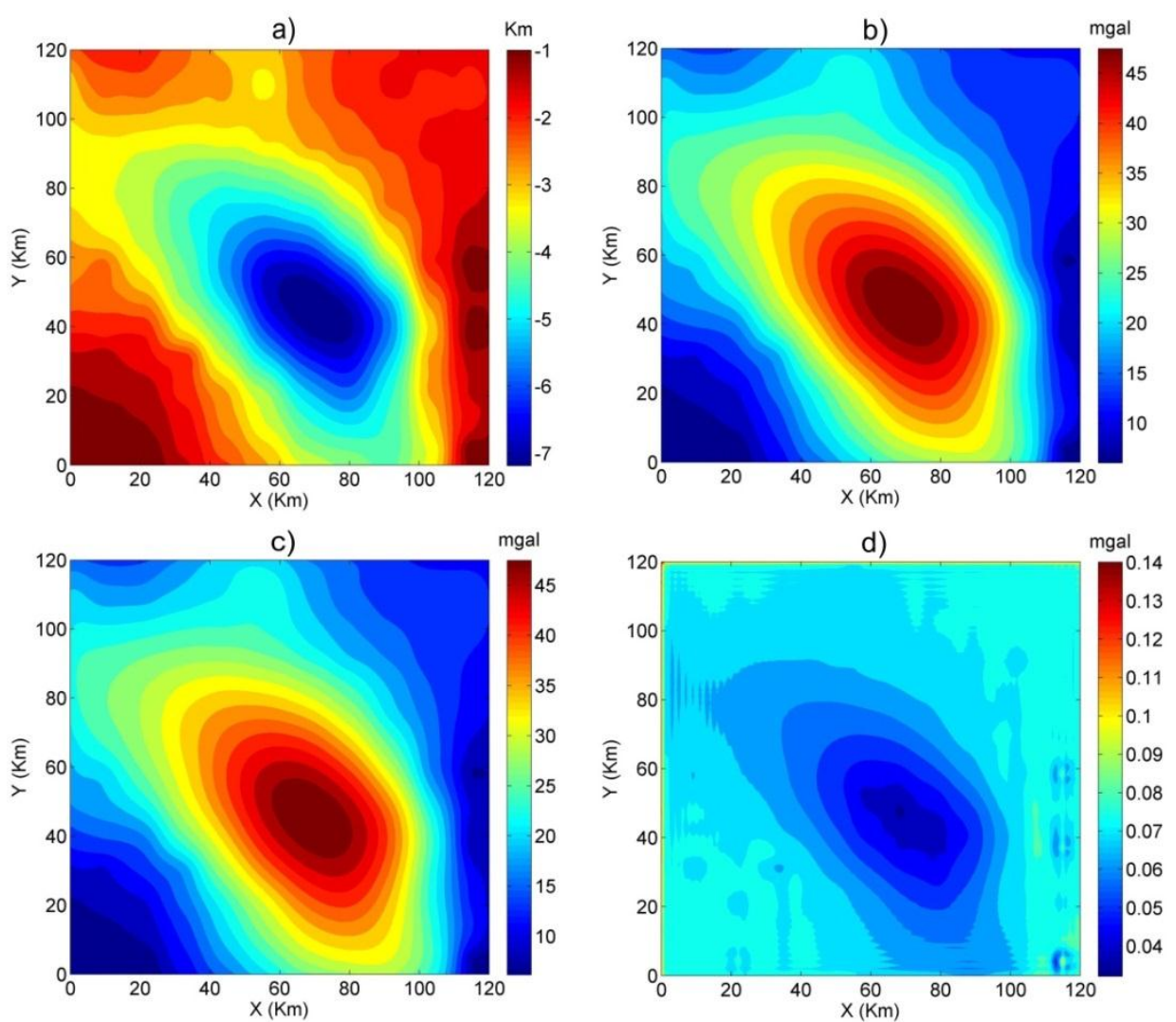

Figure 4. (a) The plan view of the first model, (b) The gravity anomalies calculated by the space domain method, (c) The gravity anomalies calculated by the frequency domain method respectively, (d) The difference between the results in Figure $4 \mathrm{~b}$ and $4 \mathrm{c}$.

Since the very complex nature of the geological phenomena, it is necessary to also test the efficiency of the methods in a more complex model. The 3D view of the complex model is shown in Figure 3. Figure 4a displays the plan view of the model. The gravity anomalies calculated by the space domain method and the frequency domain method are shown in Figure $4 \mathrm{~b}$ and $4 \mathrm{c}$, respectively. It can 
be seen from these figures that the result calculated by the space domain method compares reasonably well with those obtained from using the frequency domain method. Figure $4 \mathrm{~d}$ depicts the differences of the gravity anomalies in Figure $4 \mathrm{~b}$ and $4 \mathrm{c}$. Clearly, these differences are very small, ranging from $+0.04-+0.14 \mathrm{mgal}$. The RMS error between them is only $0.0661 \mathrm{mgal}$. In this case, the frequency domain method took only about $0.2872 \mathrm{~s}$ to calculate the anomalies on a 2-D grid of $121 \times 121$ data, while the space domain method took about $356 \mathrm{~s}$ on the same personal computer to make the similar gravity model.

\section{Application}

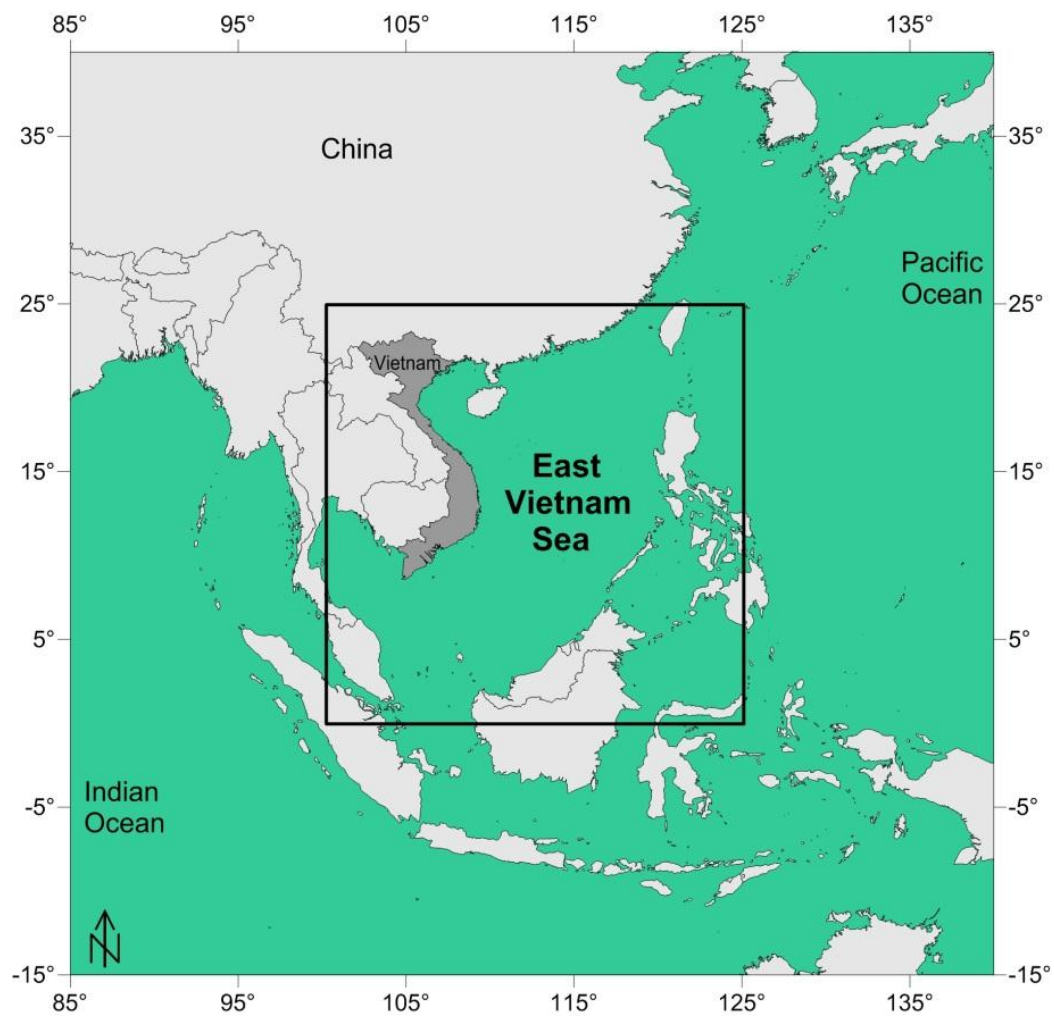

Figure 5. Location of the East Vietnam Sea and adjacent areas.

Since the frequency domain method can perform fast computations with high precision, therefore in this section, I applied it to calculate Bouguer gravity anomaly in the East Vietnam Sea and adjacent areas. Location of the area is shown in Figure 5. The area lies between $100^{\circ} \mathrm{E}$ and $125^{\circ} \mathrm{E}$ of the eastern longitudes and $0^{\circ} \mathrm{N}$ and $25^{\circ} \mathrm{N}$ of northern latitudes. To compile the Bouguer gravity map of East Vietnam Sea and adjacent areas, we used the latest available data from the TOPEX mission, which includes topographic data (version 18.1) and satellite-derived free-air gravity data (version 28.1) [28-30] (https://topex.ucsd.edu/cgi-bin/get_data.cgi). The data have a grid cell size of $1 \times 1 \mathrm{~min}$. Figure 6 and 7 show the topographic/bathymetric and free-air anomaly maps of the East Vietnam Sea and adjacent areas. The terrain correction is computed using a crustal density of $2670 \mathrm{~kg} / \mathrm{m}^{3}$ and seawater density of $1030 \mathrm{~kg} / \mathrm{m}^{3}$, and shown in Figure 8 . Figure 9 shows the complete Bouguer anomalies 
after applying the terrain correction to the free-air anomalies. It can be seen from Figure 6 and 9 that in general, the Bouguer anomalies are positive over ocean basins and negative over continental areas. The inverse relationship between the Bouguer anomalies and topography is an isostasy manifestation.

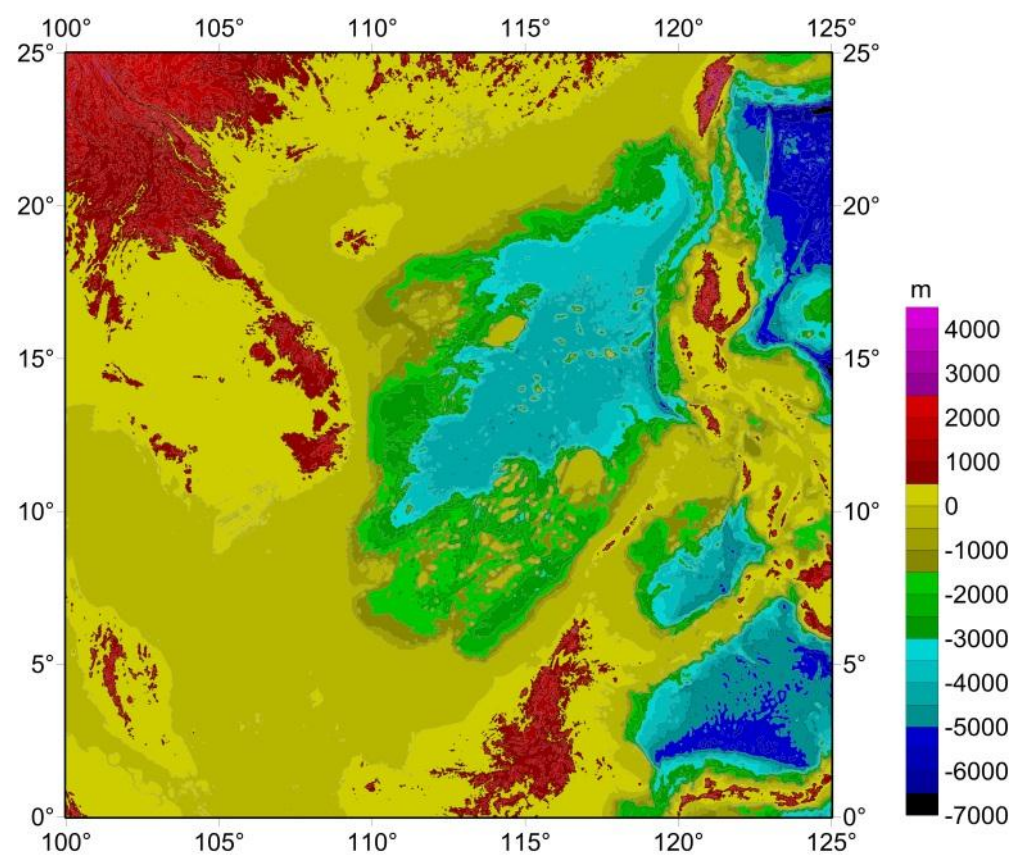

Figure 6. The topographic/bathymetric map of the East Vietnam Sea and adjacent areas.

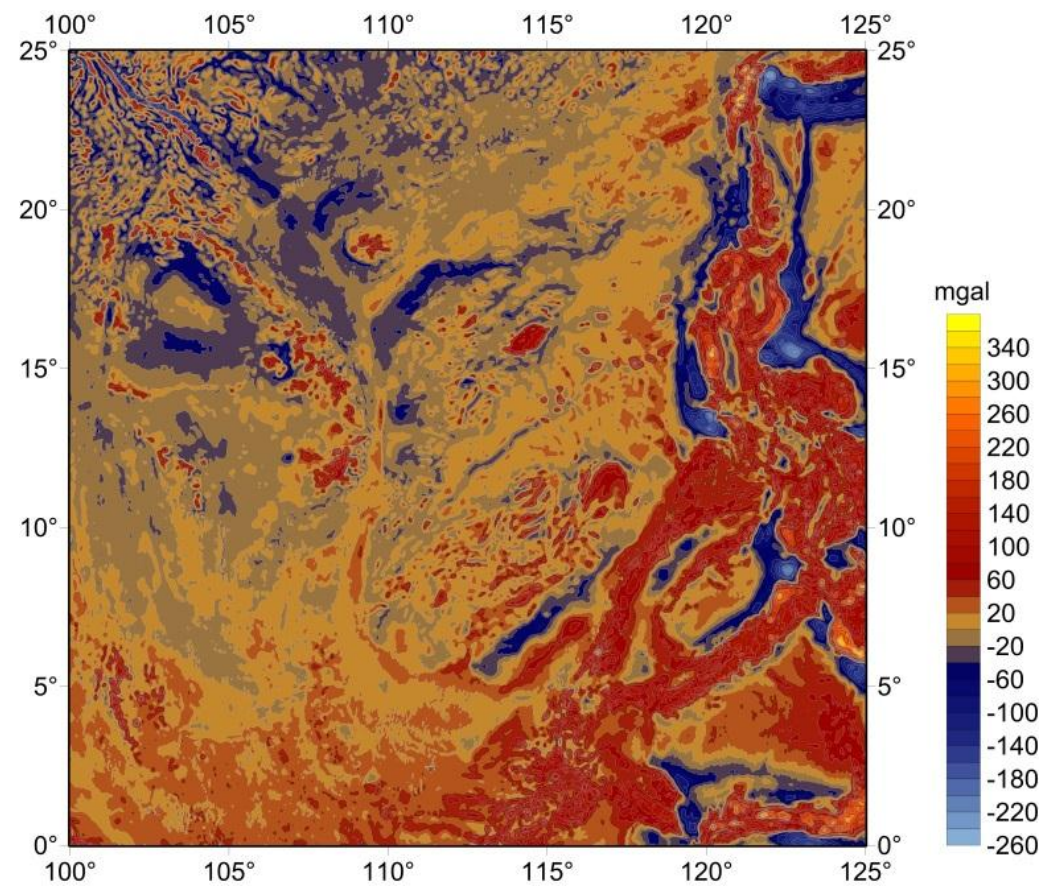

Figure 7. The Free-air anomaly map of the East Vietnam Sea and adjacent areas. 


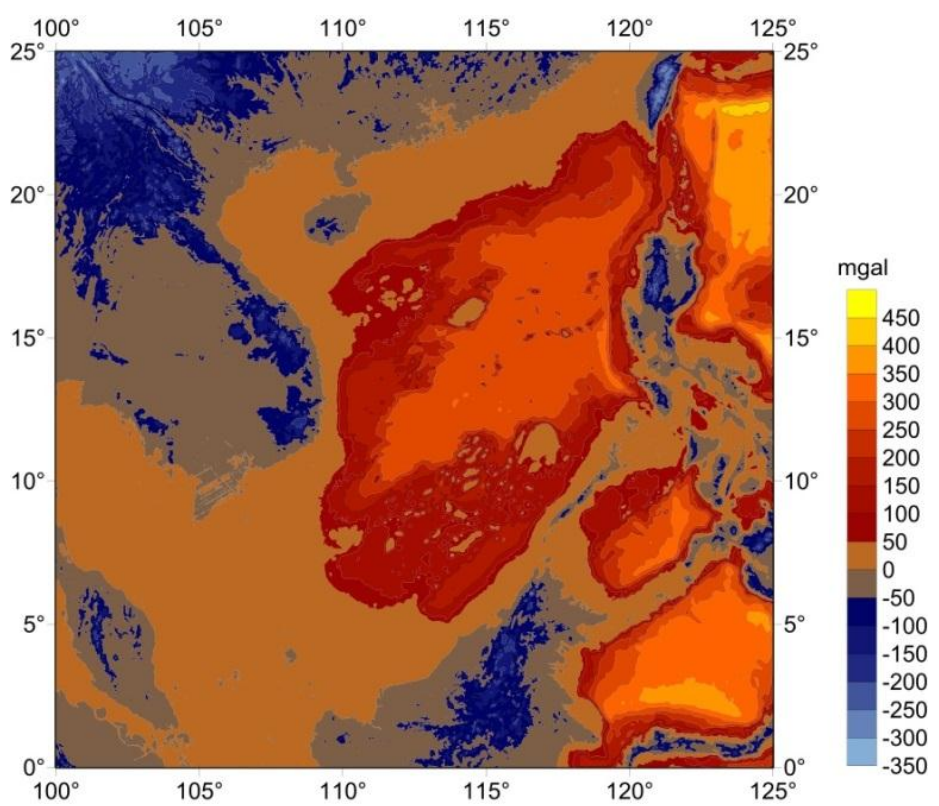

Figure 8. The terrain correction for the East Vietnam Sea and adjacent areas.

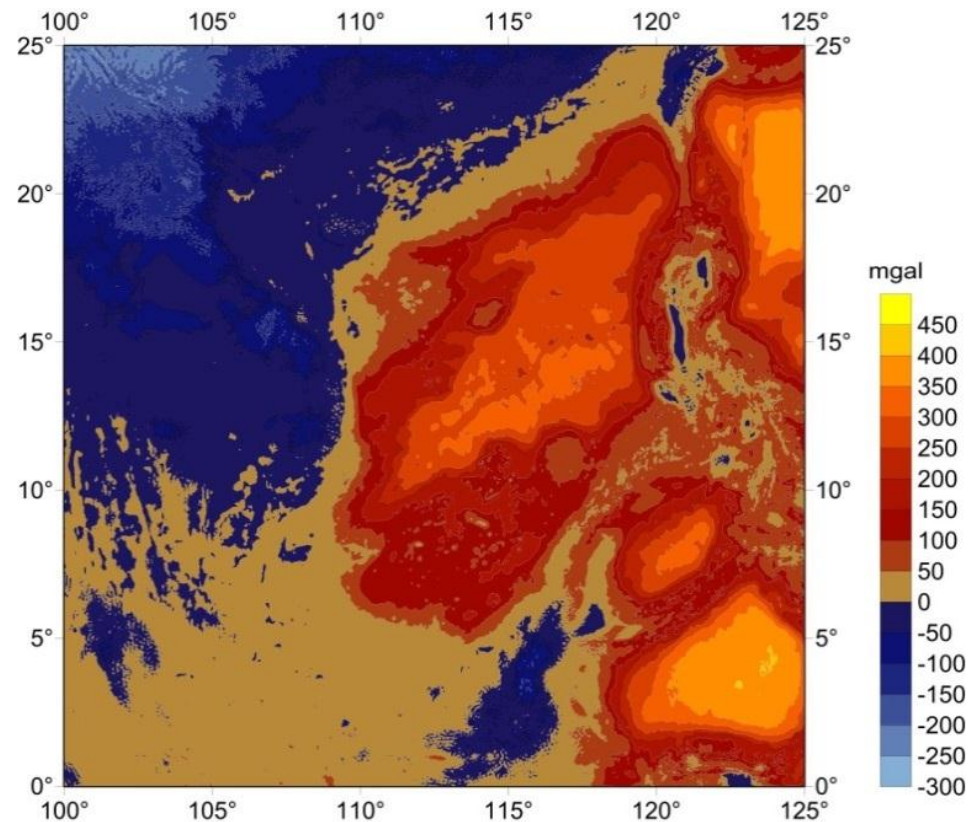

Figure 9. The Bouguer gravity anomaly map for the East Vietnam Sea and adjacent areas.

\section{Conclusion}

I tried to review the performance of the use of the space domain method of Rao et al. (1990) and the frequency domain method of Parker (1973) for calculating the gravity anomaly caused by an 
uneven layer. Test studies were performed on two synthetic models. Although the results obtained from application of the two methods are similar, the frequency domain method can perform very fast computations for the gravity effects. Finally, I applied the frequency domain method for calculating the Bouguer gravity anomaly in the East Vietnam Sea and adjacent areas using the latest available dataset from the TOPEX mission. In this case, the forward of $1498 \times 1498$ observation point mesh took only $195 \mathrm{~s}$, which is a very short time for this type of calculation. Thus, it can be concluded that the frequency domain method of Parker (1973) is an efficient tool for calculating the gravity anomaly of the $3 \mathrm{D}$ structures, making an improved quantitative interpretation possible.

\section{Acknowledgments}

This research is funded by the Vietnam National University, Hanoi (VNU) under project number QG.20.13.

\section{References}

[1] M.N. Nabighian, M.E. Ander, V.J.S. Grauch, R.O. Hansen, T.R. LaFehr, Y. Li, et al., Historical development of the gravity method in exploration, Geophysics 70 (2005) 63-89.

[2] L.T. Pham, E. Oksum, T.D. Do, GCH_gravinv: A MATLAB-based program for inverting gravity anomalies over sedimentary basins, Computers \& Geosciences 120 (2018) 40-47.

[3] E. Oksum, M.N. Dolmaz, L.T. Pham, Inverting gravity anomalies over the Burdur sedimentary basin, SW Turkey, Acta Geodaetica et Geophysica 54 (2019) 445-460.

[4] L.T. Pham, E. Oksum, T.D. Do, Edge enhancement of potential field data using the logistic function and the total horizontal gradient, Acta Geodaetica et Geophysica 54 (2019) 143-155.

[5] L.T. Pham, T.D. Do, E. Oksum, S.T. Le, Estimation of Curie point depths in the Southern Vietnam continental shelf using magnetic data, Vietnam Journal of Earth Sciences 41(2019) 216-228.

[6] A.M. Eldosouky, L.T. Pham, H. Mohammed, B. Pradhan, A comparative study of THG, AS, TA, Theta, TDX and LTHG techniques for improving source boundaries detection of magnetic data using synthetic models: a case study from G. Um Monqul, North Eastern Desert, Egypt, Journal of African Earth Sciences 170(2020) 103940.

[7] L.T. Pham, A comparative study on different filters for enhancing potential field source boundaries: synthetic examples and a case study from the Song Hong Trough (Vietnam), Arabian Journal of Geosciences 13(2020) 723.

[8] L.T. Pham, T.V. Vu, S. Le-Thi, P.T. Trinh, Enhancement of Potential Field Source Boundaries Using an Improved Logistic Filter, Pure and Applied Geophysics (2020). https://doi.org/10.1007/s00024-020-02542-9

[9] L.T. Pham, T.D. Do, Estimation of sedimentary basin depth using the hybrid technique for gravity data, VNU Journal of Science: Mathematics - Physics, 33 (2017), 48-52.

[10] L.T. Pham, E. Oksum, T.D. Do, M.D. Vu, Comparison of different approaches of computing the tilt angle of the total horizontal gradient and tilt angle of the analytic signal amplitude for detecting source edges, Bulletin of the Mineral Research and Exploration 16(2020). https://doi.org/10.19111/bulletinofmre.746858.

[11] M. Talwani, J. Worzel, M. Ladisman, Rapid gravity computations for two dimensional bodies with application to the Mendocino submarine fracture zone, Journal of Geophysical Research 64 (1959) 49-59.

[12] I.V.R. Murthy, D.B. Rao, Gravity anomalies of two-dimensional bodies of irregular cross-section with density contrast varying with depth, Geophysics 44 (1979) 1525-1530.

[13] I.V.R. Murthy, S.J. Rao, A Fortran 77 program for inverting gravity anomalies of two-dimensional basement structures, Computers \& Geosciences 15 (1989) 1149-1156

[14] J.J. Pan, Gravity anomalies of irregularly shaped two-dimensional bodies with constant horizontal density gradient, Geophysics 54 (1989) 528-530. 
[15] V.C. Rao, V. Chakravarthi, M.L. Raju, Forward modeling: Gravity anomalies of two-dimensional bodies of arbitrary shape with hyperbolic and parabolic density functions, Computers \& Geosciences 20 (1994) 873-880.

[16] S.E. Oliva, C.L. Ravazzoli, Complex polynomials for the computation of 2D gravity anomalies, Geophysical Prospecting 45 (1997) 809-818.

[17] M. Talwani, M. Ewing, Rapid computation of gravitational attraction of three-dimensional bodies of arbitrary shape, Geophysics 25 (1960) 203-225.

[18] D. Nagy, The gravitational attraction of a right rectangular prism, Geophysics 31 (1966) 362-371.

[19] H.J. Goetze, B. Lahmerger, Application of threedimensional interactive modeling in gravity and magnetics, Geophysics 53 (1988) 1096-1108.

[20] D.B. Rao, M.J. Prakash, N. Ramesh Babu, 3-D and 2 1/2-D modeling of gravity anomalies with variable density contrast, Geophysical Prospecting 38 (1990) 411-422.

[21] H. Holstein, B. Ketteridge, Gravimetric analysis of uniform polyhedra, Geophysics 61 (1996) 357-364.

[22] B. Singh, D. Guptasarma, New method for fast computation of gravity and magnetic anomalies from arbitrary polyhedra, Geophysics 66 (2001) 521-526.

[23] K. Mallesh, V. Chakravarthi, B. Ramamma, 3D gravity analysis in the spatial domain: model simulation by multiple polygonal cross-sections coupled with exponential density contrast, Pure and Applied Geophysics 176 (2019) 2497-2511.

[24] R.L. Parker, The rapid calculation of potential anomalies, Geophysisical Journal of the Royal Astronomical Society 31 (1973) 447-455.

[25] H. Granser, Three-dimensional interpretation of gravity data from sedimentary basins using an exponential density-depth function, Geophysical Prospecting 35 (1987) 1030-1041.

[26] Y. Chai, W.J. Hinze, Gravity inversion of an interface above which the density contrast varies exponentially with depth, Geophysics 53 (1988) 837-845.

[27] J. Feng, X. Meng, Z. Chen, S. Zhang, Three-dimensional density interface inversion of gravity anomalies in the spectral domain, Journal of Geophysics and Engineering 11 (2014) 035001.

[28] W.H.F. Smith, D.T. Sandwell, Global seafloor topography from satellite altimetry and ship depth soundings, Science 277 (1997) 1957-1962.

[29] D.T. Sandwell, E. Garcia, K. Soofi, P. Wessel, and W.H.F. Smith, Towards 1 mGal Global Marine Gravity from CryoSat-2, Envisat, and Jason-1, The Leading Edge, 32 (2013) 892-899.

[30] D.T. Sandwell, R.D. Müller, W.H.F. Smith, E. Garcia, R. Francis, New global marine gravity model from CryoSat-2 and Jason-1 reveals buried tectonic structure, Science 46 (2014) 65-67. 